\title{
Delay discounting, cognitive ability, and personality: What matters?
}

\author{
Yu-Hua Yeh ${ }^{1} \cdot$ Joel Myerson ${ }^{1} \cdot$ Leonard Green ${ }^{1}$ \\ Published online: 20 November 2020 \\ (C) The Psychonomic Society, Inc. 2020
}

\begin{abstract}
Steep delay discounting is associated with problems such as addiction, obesity, and risky sexual behavior that are frequently described as reflecting impulsiveness and lack of self-control, but it may simply indicate poor cognitive functioning. The present investigation took advantage of the unique opportunity provided by the Human Connectome Project $(N=1,206)$ to examine the relation between delay discounting and 11 cognitive tasks as well as the Big Five fundamental personality traits. With income level and education statistically controlled, discounting was correlated with only four of the 11 cognitive abilities evaluated, although the $r$ s were all small (<.20). Importantly, the two discounting measures loaded on their own factor. Discounting was not correlated with Neuroticism or Conscientiousness, traits related to psychometric impulsiveness and self-control. These findings suggest that steep delay discounting is not simply an indicator of poor cognitive functioning or psychometric impulsiveness but an important individual difference characteristic in its own right.
\end{abstract}

Keywords Discounting $\cdot$ Cognitive ability $\cdot$ Personality $\cdot$ Human Connectome Project $\cdot$ Decision-making

\section{Introduction}

Everyday choices between reward options are strongly affected not only by the amounts of the rewards but also by the timing of those rewards. Often, people will choose an immediate but smaller reward rather than have to wait for a larger reward. Delay discounting, the decrease in subjective value of an outcome as time until its occurrence increases, measures the psychological process underlying intertemporal choice behavior (Green, Myerson, \& Vanderveldt, 2014). Steep discounting of delayed rewards is associated with various maladaptive behaviors, including addictive behavior involving various substances (e.g., alcohol, tobacco, cocaine, and opiates) as well as gambling and obesity (Amlung, Petker, Jackson, Balodis, \& MacKillop, 2016; Amlung, Vedelago, Acker, Balodis, \& MacKillop, 2017; MacKillop et al., 2011). In addition, higher rates of delay discounting have been reported to be associated with lower grade point average (GPA; Kirby, Winston, Santiesteban, 2005) and with both

Leonard Green

LGreen@wustl.edu

1 Department of Psychological and Brain Sciences, Washington University in St. Louis, Campus Box 1125, St. Louis, MO 63130, USA earlier sexual encounters and unprotected sex in teenagers and young adults (Chesson et al., 2006).

To date, there is no consensus regarding the mechanism underlying the association of delay discounting with these behaviors, although it has been speculated that discounting may be an indicator of cognitive functioning (e.g., Shamosh \& Gray, 2008) or reflective of an overall trait of impulsiveness/self-control (e.g., Mahalingam, Stillwell, Kosinski, Rust, \& Kogan, 2014). A meta-analysis by Shamosh and Gray found a significant relation between discounting and cognitive ability, but the generality of this conclusion is open to question. More than half of the studies included in their meta-analysis were of children, and of the three that did not involve special populations (e.g., substance abusers, psychiatric patients), only one (de Wit, Flory, Acheson, McCloskey, \& Manuck, 2007) found a significant correlation between discounting and cognitive ability. Moreover, unlike the present study, most previous investigations of the relation between cognitive ability and discounting have each included only a few cognitive tasks, thereby making it difficult to determine the source of this relation.

With respect to personality traits, discounting has been reported to be related to neuroticism and conscientiousness (Mahalingam et al., 2014; Manning et al., 2014), both of which are related to impulsiveness/self-control according to the BigFive personality model (Carver, 2005; Costa \& McCrae, 1992; DeYoung, 2011). One limitation of these studies, however, is the 
failure to take into account individual differences in socioeconomic status (Jonassaint, Siegler, Barefoot, Edwards, \& Williams, 2011). Many studies of the relation between cognitive ability and delay discounting suffer from the same limitation, which is important because socioeconomic status, as measured by income and education, has been found to correlate with discounting (Green, Myerson, Lichtman, Rosen, \& Fry, 1996) as well as with cognitive ability (Ceci \& Williams, 1997; Jaroni, Wright, Lerman, \& Epstein, 2004).

The current study investigated associations between degree of discounting and cognitive abilities and personality while addressing the issues of number of cognitive measures and socioeconomic status with a sample size capable of providing definitive results. We analyzed data from 1,206 participants in the WU-Minn Human Connectome Project (HCP; Van Essen et al., 2013) who completed 11 cognitive tasks from seven cognitive domains along with discounting tasks and the 60item NEO Five-Factor Inventory (McCrae \& Costa, 2004). In addition to mapping human brain circuits and their relation to behavior in a large population of healthy adults, the HCP utilized a reliable and well-validated battery of behavioral measures that assess a wide range of human functions and behaviors (for the rationale behind the development of the behavioral battery, see Barch et al., 2013).

These data were analyzed both before and after statistically controlling for income level and education. If delay discounting were an indicator of general cognitive functioning and/or an overall impulsiveness trait, then strong and significant correlations would be expected. Discounting was correlated with a measure of general intelligence $(g)$, but when examined separately with income and education controlled, only four of the 11 cognitive measures were correlated with discounting, indicating that discounting is not simply an indicator of general cognitive function. Moreover, although a personality test specifically focused on the trait of impulsiveness was not administered, discounting was not correlated with the Neuroticism and Conscientiousness scales of the NEO (McCrae \& Costa, 2004), scales that are assumed to reflect this construct (Carver, 2005; Costa \& McCrea, 1992; DeYoung, 2011). Thus, discounting represents an important individual difference characteristic in its own right, one with significant implications for understanding a number of different behavioral problems (Bickel, Jarmolowicz, Mueller, Koffarnus, \& Gatchalian, 2012; Chabris, Laibson, Morris, Schuldt, \& Taubinsky, 2008).

\section{Method}

\section{Participants}

A sample of 1,206 individuals was obtained from the Human Connectome Project (HCP; S1200 release). Participants in the
HCP were first screened over the phone using the SemiStructured Assessment for the Genetics of Alcoholism (Bucholz et al., 1994) to identify and exclude individuals with a significant history of psychiatric disorder, substance abuse, and neurological or cardiovascular disease (for a complete description of inclusion and exclusion criteria, see Van Essen et al., 2013).

The participants were between 22 and 37 years old $(M=$ 28.84, $S D=3.69)$, 54\% female, and had 11-17 years of education $(M=14.86, S D=1.82)$. Participants reported their annual household income as being in one of eight categories (i.e., <\$10,000; \$10,000-19,999; \$20,000-29,999; \$30,000 39,999; \$40,000-49,999; \$50,000-74,999; \$75,000-99,999; $\geq \$ 100,000)$. The median income category was $5(\$ 40,000$ 49,999), with a semi-interquartile range of 2.

\section{Materials}

Delay discounting (DD) In the DD task, participants made choices between a smaller, immediate amount of (hypothetical) money and a larger, delayed amount, and an adjusting-amount procedure was used to determine the subjective value of the delayed amount (Du, Green, \& Myerson, 2002). Each participant was studied at each of the two delayed amounts (i.e., $\$ 200$ and $\$ 40,000$ ) at each of six delays in the following order: 6 months, 3 years, 1 month, 5 years, 10 years, 1 year.

For each combination of delay and amount of delayed reward (e.g., \$200 in 1 month; \$40,000 in 3 years), participants made five consecutive choices. The first choice was between the delayed amount and an immediate amount equal to onehalf the delayed amount (e.g., \$100 today vs. \$200 in 1 month; $\$ 20,000$ today vs. $\$ 40,000$ in 3 years). If the participant chose the immediate reward, then its amount was reduced on the next choice trial (e.g., \$50 today vs. \$200 in 1 month). If the participant chose the delayed reward, then the immediate amount was increased (e.g., \$150 today vs. \$200 in 1 month). The size of the adjustment after the first choice trial was half the amount of the immediate reward (e.g., a change of $\$ 50$ if the first immediate amount was \$100), and on each subsequent choice trial, the adjustment was half the amount of the prior adjustment (e.g., \$25 on the third trial), regardless of whether the participant chose the immediate or the delayed reward. The amount that would have been used for the immediate reward on a sixth choice was taken as an estimate of the subjective value (indifference point) of the delayed reward.

The area-under-the-curve $(\mathrm{AuC})$ measure was used to assess the degree of discounting for each participant at each delayed amount. The AuC is an atheoretical method for evaluating discounting that does not assume a particular mathematical model (Myerson, Green, \& Warusawitharana, 2001). The AuC equals the sum of the areas of the trapezoids created by connecting the data points (i.e., the indifference points) and 
then projecting a straight line from each point to the $\mathrm{x}$-axis. The AuC can range from near 0.00 (complete discounting) to close to 1.00 (no discounting); the greater the degree of discounting, the lower the AuC.

Cognitive tasks Below are brief descriptions of the 11 tests studied within the seven cognitive domains (for test details, see Gur et al., 2001, and Slotkin et al., 2012).

\section{Fluid intelligence}

1) Raven's Progressive Matrices (RPM) presents patterns that have one missing figure, and participants are asked to pick the figure that best fits the pattern from five alternatives. Scores represent the number of correct responses.

\section{Executive function}

2) The Dimensional Change Card Sort Test (DCCS) is a measure of cognitive flexibility in which a target visual stimulus is displayed, and participants are asked to pick which of two choice stimuli best matches the target on either shape or color. Scores are based on a combination of accuracy and reaction time.

3) The Flanker Inhibitory Control and Attention Test (FICA) is a measure of inhibitory control. Participants are asked to indicate which way a target arrow is pointing while ignoring other distractor arrows. Scores are based on a combination of accuracy and reaction time.

\section{Memory}

4) The List Sorting Working Memory Test (LSWM) is a measure of working memory. Participants see pictures and hear the names of various animals and types of food and are asked to report them in order of size (from smallest to largest). Scores represent the total number of items correctly recalled and sequenced.

5) The Penn Word Memory Test (PWM) is a measure of verbal episodic memory. Participants are shown 20 tobe-remembered words followed by a recognition test consisting of a list 40 words (a combination of 20 previously presented words and 20 new words matched on memory-related characteristics) and are asked to indicate which ones they have seen previously. Scores represent the number of correct responses.

6) The Picture Sequence Memory Test (PSM) is a measure of non-verbal episodic memory. Participants are asked to memorize and then recall the order of increasingly lengthy series of illustrated objects and activities. Scores represent the number of adjacent pairs of pictures correctly recalled.

\section{Sustained attention}

7) In the Short Penn Continuous Performance Test (SPCP), participants see vertical and horizontal lines added sequentially to a seven-segment display and are asked to report when the lines form a letter or a number and what it was. Analysis was based on the sensitivity measure (i.e., the number of true positives divided by the total number of true positives and false negatives).

\section{Processing speed}

8) In the Pattern Comparison Processing Speed Test $(P C P S)$, participants are asked to indicate whether two side-by-side pictures are the same or not. Scores represent the number of correct responses in a 90 -s period.

\section{Spatial orientation}

9) In the Variable Short Penn Line Orientation Test (VSPLO), participants are presented with a red and blue line and instructed to use arrow keys to turn the blue line until it appears parallel to the red one. The length of the red line is always the same, while the length of the blue line can be shorter or longer than the red line. Scores represent the number of correct responses.

\section{Language}

10) The Oral Reading Recognition Test (ORR) is a measure of reading decoding skill. Participants see words on a screen and are asked to pronounce them as accurately as possible. Scores represent the number of words pronounced correctly.

11) The Picture Vocabulary Test (PV) is a measure of vocabulary comprehension in which participants hear a word and are asked to choose the picture on the screen that best matches the meaning of that word. Scores represent the number of correct choices.

NEO Five-Factor Inventory The 60 -item version of the Costa and McCrae Neuroticism/Extroversion/Openness Five Factor Inventory measures the five major facets of human personality: (1) Neuroticism; (2) Extroversion/Introversion; (3) Openness; (4) Agreeableness; (5) Conscientiousness (McCrae \& Costa, 2004).

\section{Procedure}

For the HCP, participants were first screened over the phone using the Semi-Structured Assessment for the Genetics of 
Alcoholism (Bucholz et al., 1994). Eligible participants were invited to the lab and took different tests over 2 days, including the non-NIH toolbox cognitive tests on the first day and the tests from the Cognition Battery of the NIH toolbox on the second day. Information on the NIH toolbox is available at http://www.healthmeasures.net/explore-measurementsystems/nih-toolbox/intro-to-nih-toolbox/cognition. Both sets of tests took approximately $1.5 \mathrm{~h}$ each and occurred in the late morning, just before the participants' lunch break.

\section{Data analysis}

Only the measures from the HCP that were relevant to the current study were retrieved and analyzed (see Materials). Missing values comprised $0.004 \%$ of the selected data and were imputed by predictive mean matching. Intercorrelations among delay discounting, the 11 cognitive measures, and the five personality traits were calculated, both with and without statistically controlling for individual differences in income and education. The significance of each Pearson correlation coefficient was determined after applying a Bonferroni-Holm correction to avoid an inflated Type-I error rate due to multiple hypothesis testing (Holm, 1979). The correlation of discounting with a measure of general intelligence $(g)$ obtained using principle components analysis also was calculated. To further investigate the relations between delay discounting and cognitive abilities, we conducted exploratory factor analyses using Oblimin rotation on both the first-order correlation

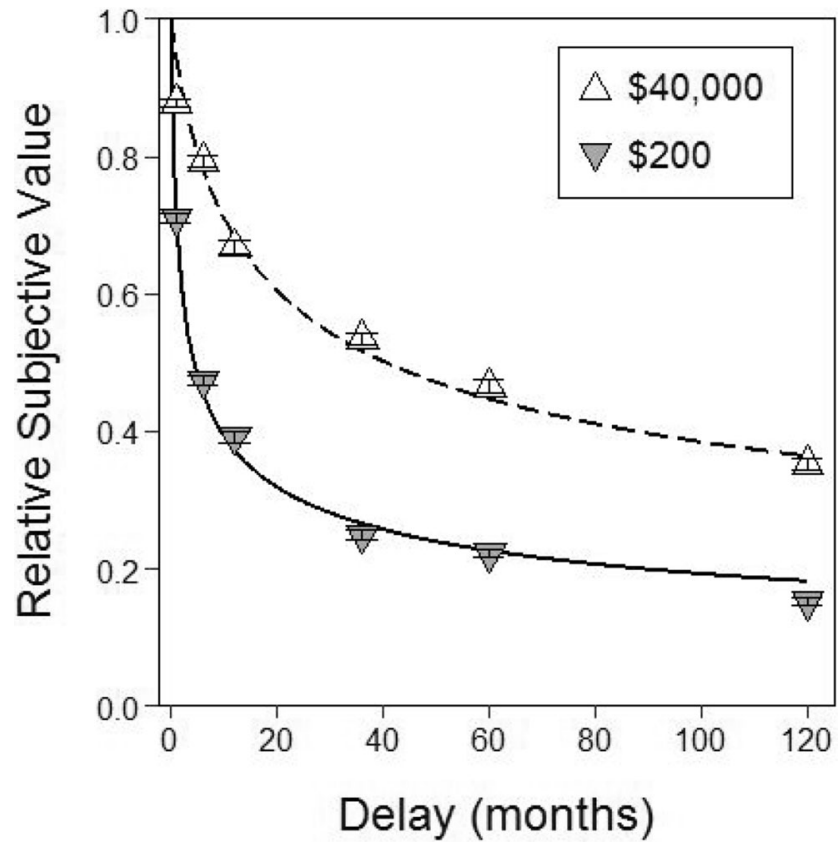

Fig. 1 Relative subjective value of the $\$ 200$ (gray downward triangle) and $\$ 40,000$ (white upward triangle) rewards as a function of delay. For each reward at each delay, the relative subjective value (indifference point) represents the mean amount of immediate reward equivalent in value to the delayed reward (error bars represent standard errors) matrix and the partial correlation matrix (i.e., the correlations after controlling for income and education).

\section{Results}

Figure 1 shows the group mean subjective values (i.e., the indifference points) for each delayed amount at each delay. The expected magnitude effect (shallower discounting of the larger delayed amount; Green \& Myerson, 2004) may be seen. The curves represent the best-fitting hyperboloid discounting model (Myerson \& Green, 1995) with a single scaling exponent and separate rate parameters for the smaller and larger amounts $\left(R^{2}=.987\right)$.

Following Shamosh et al. (2008), we examined the relation between a $g$ factor obtained via a principal components analysis of the raw scores on the eleven cognitive tests, shown in Table 1, and the discounting of delayed rewards. Participants' discounting rates (measured as AuCs) were significantly correlated with $g$ ( $r \mathrm{~s}=.21$ and .25 for the smaller and larger delayed amounts, respectively) indicating that those with higher intelligence scores discounted less steeply (as indicated by larger AuCs) than those with lower scores.

There was a strong correlation between the discounting of the two delayed amounts $(r=.67)$, and all but two of the 55 correlations among the cognitive measures were significant (see Online Supplemental Table S1). Table 2 presents the

Table 1 Loadings of the raw scores on the Connectome Cognitive Tasks on the First Principal Component of a Principal Components Analysis

\begin{tabular}{ll}
\hline Tasks & Loadings \\
\hline RPM & $\mathbf{. 6 9}$ \\
DCCS & .55 \\
FICA & .45 \\
LSWM & .58 \\
PWM & .42 \\
PSM & .50 \\
SPCP & .37 \\
PCPS & .45 \\
VSPLO &. $\mathbf{6 3}$ \\
ORR & $\mathbf{7 5}$ \\
PV & $\mathbf{. 7 2}$ \\
\hline
\end{tabular}

Cognitive tasks loading on factors that subsequent analyses show are correlated with discounting are in bold

RPM Raven's Progressive Matrices, DCCS Dimensional Change Card Sort Test, FICA Flanker Inhibitory Control and Attention Test, LSWM List Sorting Working Memory Test, $P W M$ Penn Word Memory Test; $P S M$ Picture Sequence Memory Test, SPCP Short Penn Continuous Performance Test, PCPS Pattern Comparison Processing Speed Test, VSPLO Variable Short Penn Line Orientation Test, ORR Oral Reading Recognition Test, $P V$ Picture Vocabulary Test 
Table 2 Correlations between delay discounting and cognitive abilities and personality before and after controlling for income and education

\begin{tabular}{|c|c|c|c|c|}
\hline & \multicolumn{2}{|c|}{ Before } & \multicolumn{2}{|l|}{ After } \\
\hline & $\mathrm{DD}_{\mathrm{Sm}}$ & $\mathrm{DD}_{\mathrm{Lg}}$ & $\mathrm{DD}_{\mathrm{Sm}}$ & $\mathrm{DD}_{\mathrm{Lg}}$ \\
\hline $\mathrm{DD}_{\mathrm{Sm}}$ & - & $.67 * *$ & - & $.66^{* *}$ \\
\hline $\mathrm{DD}_{\mathrm{Lg}}$ & & - & & - \\
\hline RPM & $.18^{* *}$ & $.20 * *$ & $.12 * *$ & $.13^{* *}$ \\
\hline DCCS & .00 & .06 & -.03 & .00 \\
\hline FICA & .02 & .04 & -.00 & .02 \\
\hline LSWM & $.11 * *$ & $.10 *$ & .07 & .04 \\
\hline PWM & .07 & $.10 *$ & .04 & .06 \\
\hline PSM & .08 & .06 & .03 & .00 \\
\hline SPCP & .07 & $.12 * *$ & .02 & .07 \\
\hline PCPS & .02 & .04 & -.00 & .00 \\
\hline VSPLO & $.14 * *$ & $.21 * *$ & $.11^{*}$ & $.16^{* *}$ \\
\hline ORR & $.21 * *$ & $.25 * *$ & $.14 * *$ & $.17 * *$ \\
\hline PV & $.25^{* *}$ & $.27 * *$ & $.18^{* *}$ & $.19 * *$ \\
\hline NEO-N & -.06 & -.05 & -.06 & -.03 \\
\hline NEO-E & .02 & .02 & .03 & .02 \\
\hline NEO-O & $.17 * *$ & $.11 * *$ & $.15^{* *}$ & .09 \\
\hline NEO-A & .06 & $.13 * *$ & .05 & $.10^{*}$ \\
\hline NEO-C & -.03 & -.03 & -.02 & -.03 \\
\hline
\end{tabular}

$D D_{S m}$ Delay Discounting Task (\$200), $D D_{L g}$ Delay Discounting Task (\$40,000), RPM Raven's Progressive Matrices, DCCS Dimensional Change Card Sort Test, FICA Flanker Inhibitory Control and Attention Test, LSWM List Sorting Working Memory Test, PWM Penn Word Memory Test; PSM Picture Sequence Memory Test, SPCP Short Penn Continuous Performance Test, PCPS Pattern Comparison Processing Speed Test, VSPLO Variable Short Penn Line Orientation Test, ORR Oral Reading Recognition Test, $P V$ Picture Vocabulary Test, $N E O-N$ neuroticism, $N E O-E$ extroversion, $N E O-O$ openness, $N E O-A$ agreeableness, $N E O-C$ conscientiousness

$* p<.05 ; * * p .01$

correlations between the two discounting measures and the scores on all the cognitive and personality measures, both before and after controlling for income and education. As may be seen, the raw scores on five of the 11 cognitive measures (i.e., RPM, LSWM, VSPLO, ORR, and PV) were significantly correlated with discounting of both delayed amounts. With respect to the personality measures, discounting was not correlated with either Neuroticism or Conscientiousness, traits related to self-control as measured by psychometric tests of impulsiveness (for a review, see Carver, 2005), although discounting of the larger reward was significantly correlated with Agreeableness, another trait that may be related to impulsiveness (Carver, 2005; DeYoung, 2011).

As expected, both of the discounting measures and the raw scores on all but one of the cognitive tasks were significantly correlated with income and with education (see Online
Supplemental Table S2). Therefore, we calculated the partial correlations with the discounting measures in order to control for these demographic variables. After controlling for income and education, the pattern of correlations was similar to that for the first-order correlations, although now only four cognitive measures and none of the personality measures were correlated with both discounting measures. This may be seen if one compares the two leftmost columns with the two rightmost columns of Table 2 (also compare Online Supplemental Tables S1 and S3). It is to be noted that for those cognitive tasks where the correlations had been significant, controlling for measures of socioeconomic status (SES) decreased the $r$ by a third, from a mean of .18 to .12 .

To further examine the relations between delay discounting and cognitive abilities, exploratory factor analyses with Oblimin rotation were performed on the partial correlation matrices. Following the guideline described in Costello and Osborne (2005), both PWM (verbal episodic memory) and SPCP (sustained attention) were removed from the analysis because their loadings were less than the minimum of .32 on all factors. A five-factor solution (see Table 3) was obtained that accounted for $50 \%$ of the standardized variance. The weak association between discounting and performance on the different cognitive tasks observed in the correlation was also evident in the finding that delay discounting loaded on its own factor (Factor 1).

Table 3 Factor loadings for exploratory factor analysis with Oblimin rotation of DD task and cognitive tests

\begin{tabular}{|c|c|c|c|c|c|}
\hline & $\begin{array}{l}\text { Factor- } \\
1\end{array}$ & $\begin{array}{l}\text { Factor- } \\
2\end{array}$ & $\begin{array}{l}\text { Factor- } \\
3\end{array}$ & $\begin{array}{l}\text { Factor- } \\
4\end{array}$ & $\begin{array}{l}\text { Factor- } \\
5\end{array}$ \\
\hline $\mathrm{DD}_{\mathrm{Sm}}$ & .83 & .01 & -.02 & .04 & -.06 \\
\hline $\mathrm{DD}_{\mathrm{Lg}}$ & .82 & .00 & .02 & -.05 & .06 \\
\hline RPM & .03 & .24 & -.05 & .26 & .35 \\
\hline DCCS & -.01 & -.03 & .70 & .04 & .08 \\
\hline FICA & .01 & .04 & .73 & -.07 & -.01 \\
\hline LSWM & -.01 & .14 & .01 & .48 & .07 \\
\hline PSM & .01 & -.06 & .05 & .62 & -.01 \\
\hline PCPS & .01 & .02 & .54 & .14 & -.10 \\
\hline VSPLO & .04 & .03 & .07 & .02 & .65 \\
\hline ORR & .01 & .64 & .02 & .04 & .19 \\
\hline PV & .01 & .94 & .01 & -.01 & -.05 \\
\hline
\end{tabular}

Factor loadings $>.32$ are in boldface

$D D_{S m}$ Delay Discounting Task (\$200), $D D_{L g}$ Delay Discounting Task (\$40,000), RPM Raven's Progressive Matrices, DCCS Dimensional Change Card Sort Test, FICA Flanker Inhibitory Control and Attention Test, $L S W M$ List Sorting Working Memory Test, $P W M$ Penn Word Memory Test; $P S M$ Picture Sequence Memory Test, SPCP Short Penn Continuous Performance Test, PCPS Pattern Comparison Processing Speed Test, VSPLO Variable Short Penn Line Orientation Test, ORR Oral Reading Recognition Test, $P V$ Picture Vocabulary Test 
Table 4 Intercorrelations among factors

\begin{tabular}{llllll}
\hline Factors & 1 & 2 & 3 & 4 & 5 \\
\hline 1. Discounting & - & $.25(.34)$ & $-.01(.05)$ & $.06(.15)$ & $.19(.25)$ \\
2. Language & & - & $.22(.28)$ & $.30(.43)$ & $.51(.56)$ \\
3. Exec/Speed & & & - & $.31(.35)$ & $.29(.32)$ \\
4. Working Memory & & & - & $.38(.44)$ \\
5. Visuospatial & & & & - \\
\hline
\end{tabular}

Note. Factor names are based on the names of the functions captured by the cognitive measures loading on them (see Table 3); tests of both Executive Function and Processing Speed loaded on the Exec/Speed factor (Factor 3 in Table 3); both the VSPLO and the RPM tests loaded on the visuospatial factor. The correlations before controlling for income and education are italicized and in parentheses; the correlations after controlling for income and education are not italicized

Table 4 presents the intercorrelations among the five factors. As may be seen, discounting (Factor 1) was related to language ability (Factor 2) and to another factor (Factor 5) that reflected visuospatial perception and, to a much lesser extent, fluid intelligence as measured by the RPM. Notably, the four measures loading on Factors 2 and 5 also had the four strongest loadings on the first principle component used to measure $g$, which in turn, correlated with both discounting measures. Finally, despite the correlation between the RPM and discounting, neither Factor 3, on which three of the five measures of the Connectome's fluid composite loaded, nor Factor 4 , on which the other two measures of the fluid composite loaded, correlated with Factor 1, the discounting factor $(r \mathrm{~s}=$ -.01 and .06, respectively). A similar pattern of correlations among factors was observed in an exploratory factor analysis of the data before controlling for income and education (shown in parentheses in Table 4), but perhaps not unexpectedly, those correlations were all higher than with income and education statistically controlled.

\section{Discussion}

Steep delay discounting has been shown to be associated with various behavioral problems (Bickel et al., 2012), most notably substance abuse (MacKillop et al., 2011), but the underlying mechanisms remain unknown. Previous findings suggested that the degree of discounting may simply be an indicator of intelligence (e.g., Shamosh \& Gray, 2008) or impulsiveness (e.g., Mahalingam et al., 2014). The current study examined these two conjectures using data from the Human Connectome Project and evaluated the correlations between delay discounting measures and performance on 11 cognitive tasks and the Big-Five personality traits in a sample of 1,206 young adults. Little support was found for the idea that steep delay discounting reflects psychometric impulsiveness or a lack of self-control. Although participants' discounting rates were significantly correlated, albeit weakly, with a general intelligence factor $(g)$, this turned out to be due to correlations with only a few of the cognitive tasks and in part reflected variance shared with demographic factors (i.e., income and education). Notably, whereas demographic factors played significant roles in the relations between decision making and other cognitive functions, these factors played much less of a role in the relations between personality traits and decisionmaking involving delayed rewards.

The decreases in the strength of correlations between discounting rates and cognitive and personality measures observed after controlling for income and education raise the possibility that measures of SES are causally related to discounting. This causality is likely bi-directional. For example, manipulating people's resource availability changes the degree to which they discount (e.g., Shah et al. 2012), and steep discounting is associated with problem behaviors such as substance use (e.g., Bickel et al., 2012) that may affect educational attainment as well as job performance. Thus, the present findings call for more research to disambiguate these causal relations and to more clearly identify the underlying mechanisms (Diemer et al., 2013).

\section{Cognitive abilities and discounting}

The rates at which both the smaller and larger delayed rewards were discounted were both correlated with $g$, albeit weakly. However, scores on all but one of the cognitive measures were significantly correlated with both income and education, and after controlling for these demographic measures, only four of the 11 cognitive measures (Raven's Progressive Matrices, a measure of visuospatial ability, and two language ability measures) were correlated with the discounting measures, and these correlations were all quite small $(r s<.20)$.

The weak association between delay discounting and cognitive abilities was confirmed by exploratory factor analysis based on the partial correlations among the measures, with income and education controlled. Discounting of both a small and a large delayed reward loaded strongly on a single factor, with both loadings $>.80$, whereas the loadings of the cognitive measures on the discounting factor were all less than .05 . There were also four cognitive factors, two of which correlated with the discounting factor, again suggesting that the relation between discounting and cognitive abilities is specific rather than general in nature, once demographic factors are controlled.

The two factors that did correlate with discounting represented language and visuospatial abilities. Interestingly, while the RPM loaded on the visuospatial factor, its loading (.34) was half that of the line orientation (VSPLO) test that also loaded on this factor, suggesting that the factor was visuospatial rather than fluid in nature, particularly as the five tests 
making up the Connectome fluid construct loaded on the two factors that did not correlate with discounting. One of these was a working memory factor, as indicated by the fact that the LSWM and PSM tests loaded on this factor. The other factor that did not correlate with discounting was an executive/speed factor, as indicated by the fact that the tests loading on it were the DICCS and the FICA tests, both measures of executive function, and the PCPS, a pure speed measure. The fact that neither of these two factors correlated with the discounting factor provides further support for the idea that the relation of cognitive abilities to discounting is specific rather than general in nature.

Previously, discounting has been reported to relate to executive function and working memory (e.g., Hinson, Jameson, \& Whitney, 2003; Shamosh et al., 2008; Weatherly \& Ferraro, 2011). Although Shamosh et al. found that working memory predicted delay discounting, they noted that it accounted for no unique variance beyond that accounted for by the $g$ factor. In four experiments, Hinson et al. found that a working memory load increased discounting, which is a separate issue from the individual differences question examined here. Indeed, the Connectome data show that working memory is unrelated to discounting after controlling for income and education. The one experiment in Hinson et al. that did investigate individual differences (Experiment 3) did not examine differences in working memory. Interestingly, they found that a group of undergraduates with high scores on a neuropsychological dysexecutive scale (Burgess, Alderman, Evans, Emslie, \& Wilson, 1998) discounted more steeply than a group with low scores, and were more affected by the working memory load associated with having to choose between four options, rather than just between an immediate and a delayed reward. Weatherly and Ferraro also administered a neuropsychological executive function questionnaire (Spinella, 2005) to undergraduates and found that it correlated with delay discounting even after controlling for parental income. However, the questions did not address the fundamental aspects of executive function of concern to cognitive psychologists like those assessed by the Connectome task battery.

\section{Personality traits and discounting}

With respect to impulsiveness, the term long preferred by psychometricians (e.g., Stanford et al., 2009), measures of delay discounting were not correlated with scores on Neuroticism or Conscientiousness, traits said to be related to impulsiveness and self-control (Carver, 2005; Costa \& McCrea, 1992). Although previous studies have found significant correlations between discounting and Neuroticism and Conscientiousness (Manning et al., 2014; Mahalingam et al., 2014), the present study is the first to investigate these relations while controlling for socioeconomic status. Previous findings have been mixed with respect to the relations between discounting and psychometric impulsiveness, but a recent study with a sample size comparable to the present one (MacKillop et al., 2016) found that the correlation between a latent discounting construct, which they termed impulsive choice, and a psychometric impulsiveness construct was only .10 , although it should be noted that, as in most previous studies, individual differences in SES were not statistically controlled. The Connectome data did reveal significant correlations between delay discounting measures and scores on the Agreeableness and Openness scales of the NEO after controlling for income and education, but neither of these correlations was consistent across both delayed amounts (see Table 2).

We do not intend to argue that delay discounting has no relation to psychometric impulsiveness since the measure used in the current study assessed broader personality traits. Nevertheless, we believe our findings provide a clear message that delay discounting measures bear relatively little relation to the Big-Five personality traits. In combination with the fact that the correlations between delay discounting and self-report measures of impulsiveness in the literature are inconsistent and at best weak (de Wit et al., 2007; Reynolds, Ortengren, Richards, \& de Wit, 2006), it is apparent that delay discounting does not simply reflect a personality trait of impulsiveness. Perhaps in recognition of the weakness of the relations involved, researchers now often define discounting operationally as a measure of "impulsive choice" (e.g., MacKillop et al., 2016), perhaps to distinguish it from impulsiveness as measured by psychometricians (e.g., Stanford et al., 2009).

\section{Conclusion}

The present investigation took advantage of the unique opportunity provided by the Human Connectome Project to examine the relations between the discounting of delayed rewards and various cognitive functions as well as the five fundamental personality traits assessed by the NEO. The current findings suggest that steep discounting, a behavior strongly related to behavioral problems, is not simply an indicator of generally poor cognitive functioning or a measure of impulsiveness in healthy young adults as assessed by personality tests, but is an important individual difference characteristic in its own right.

Acknowledgements Data were provided by the Human Connectome Project, WU-Minn Consortium (Principal Investigators: David Van Essen and Kamil Ugurbil; 1U54MH091657), funded by the $16 \mathrm{NIH}$ Institutes and Centers that support the NIH Blueprint for Neuroscience Research and by the McDonnell Center for Systems Neuroscience at Washington University. Preparation of the manuscript was supported by the National Institute on Aging of the National Institutes of Health under Award Number R01AG058885. We are grateful to Rebecca Williams and Yanjie Zhou for their assistance with initial analyses of the data. 


\section{References}

Amlung, M., Petker, T., Jackson, J., Balodis, I., \& MacKillop, J. (2016). Steep discounting of delayed monetary and food rewards in obesity: A meta-analysis. Psychological Medicine, 46(11), 2423-2434. https://doi.org/10.1017/S0033291716000866

Amlung, M., Vedelago, L., Acker, J., Balodis, I., \& MacKillop, J. (2017). Steep delay discounting and addictive behavior: A meta-analysis of continuous associations. Addiction, 112(1), 51-62. https://doi.org/ 10.1111/add. 13535

Barch, D. M., Burgess, G. C., Harms, M. P., Petersen, S. E., Schlaggar, B. L., Corbetta, M., Glasser, M. F., Curtiss, S., Dixit, S., Feldt, C., Nolan, D., Bryant, E., Hartley, T., Footer, W., Bjork, J. M., Poldrack, R., Smith, S., Johansen-Berg, H., Snyder, A. Z., \& Van Essen, D. C., for the WU-Minn HCP Consortium. (2013). Function in the human connectome: Task-fMRI and individual differences in behavior. NeuroImage, 80, 169-189. https://doi.org/10.1016/j. neuroimage.2013.05.033

Bickel, W. K., Jarmolowicz, D. P., Mueller, E. T., Koffarnus, M. N., \& Gatchalian, K. M. (2012). Excessive discounting of delayed reinforcers as a trans-disease process contributing to addiction and other disease-related vulnerabilities: Emerging evidence. Pharmacology \& Therapeutics, 134(3), 287-297. https://doi.org/10.1016/j. pharmthera.2012.02.004

Bucholz, K. K., Cadoret, R., Cloninger, C. R., Dinwiddie, S. H., Hesselbrock, V. M., Nurnberger, Jr. J. I., ... Schuckit, M. A. (1994). A new, semi-structured psychiatric interview for use in genetic linkage studies: A report on the reliability of the SSAGA. Journal of Studies on Alcohol and Drugs, 55(2), 149-158. https:// doi.org/10.15288/jsa.1994.55.149

Burgess, P. W., Alderman, N., Evans, J., Emslie, H., \& Wilson, B. A. (1998). The ecological validity of tests of executive functions. Journal of the International Neuropsychological Society, 4(6), 547-558. https://doi.org/10.1017/S1355617798466037

Carver, C. S. (2005). Impulse and constraint: Perspectives from personality psychology, convergence with theory in other areas, and potential for integration. Personality and Social Psychology Review, 9(4), 312-333. https://doi.org/10.1207/s15327957pspr0904_2

Ceci, S. J., \& Williams, W. M. (1997). Schooling, intelligence, and income. American Psychologist, 52(10), 1051-1058. https://doi.org/ 10.1037/0003-066X.52.10.1051

Chabris, C. F., Laibson, D., Morris, C. L., Schuldt, J. P., \& Taubinsky, D. (2008). Individual laboratory-measured discount rates predict field behavior. Journal of Risk and Uncertainty, 37, 237-269. https://doi. org/10.1007/s11166-008-9053-x

Chesson, H. W., Leichliter, J. S., Zimet, G. D., Rosenthal, S. L., Bernstein, D. I., \& Fife, K. H. (2006). Discount rates and risky sexual behaviors among teenagers and young adults. Journal of Risk and Uncertainty, 32, 217-230. https://doi.org/10.1007/ s11166-006-9520-1

Costa, P. T., \& McCrae, R. R. (1992). Professional manual: Revised NEO personality inventory (NEO-PI-R) and NEO five-factor inventory (NEO-FFI). Odessa, FL: Psychological Assessment Resources.

Costello, A. B., \& Osborne, J. W. (2005). Best practices in exploratory factor analysis: Four recommendations for getting the most from your analysis. Practical Assessment, Research \& Evaluation, 10, 7. https://pareonline.net/pdf/v10n7.pdf

de Wit, H., Flory, J. D., Acheson, A., McCloskey, M., \& Manuck, S. B. (2007). IQ and nonplanning impulsivity are independently associated with delay discounting in middle-aged adults. Personality and Individual Differences, 42(1), 111-121. https://doi.org/10.1016/j. paid.2006.06.026

DeYoung, C. G. (2011). Impulsivity as a personality trait. In K. D. Vohs \& R. F. Baumeister (Eds.), Handbook of self-regulation: Research, theory, and applications (2nd, pp. 485-502). New York: Guilford Press. https://psycnet.apa.org/record/2010-24692-026

Diemer, M. A., Mistry, R. S., Wadsworth, M. E., López, I., \& Reimers, F. (2013). Best practices in conceptualizing and measuring social class in psychological research. Analyses of Social Issues and Public Policy, 13(1), 77-113. https://doi.org/10.1111/asap.12001

Du, W., Green, L., \& Myerson, J. (2002). Cross-cultural comparisons of discounting delayed and probabilistic rewards. Psychological Record, 52, 479-492. https://doi.org/10.1007/BF03395199

Green, L., \& Myerson, J. (2004). A discounting framework for choice with delayed and probabilistic rewards. Psychological Bulletin, 130(5), 769. https://doi.org/10.1037/0033-2909.130.5.769

Green, L., Myerson, J., Lichtman, D., Rosen, S., \& Fry, A. (1996). Temporal discounting in choice between delayed rewards: The role of age and income. Psychology and Aging, 11(1), 79-84. https:// psycnet.apa.org/buy/1996-03617-009

Green, L., Myerson, J., \& Vanderveldt, A. (2014). Delay and probability discounting. In F. K. McSweeney \& E. S. Murphy (Eds.), The Wiley Blackwell handbook of operant and classical conditioning (pp. 307337). Chichester, West Sussex: John Wiley \& Sons, Ltd. https://doi. org/10.1002/9781118468135.ch13

Gur, R. C., Ragland, J. D., Moberg, P. J., Turner, T. H., Bilker, W. B., Kohler, C., ... Gur, R. E. (2001). Computerized neurocognitive scanning: I. methodology and validation in healthy people. Neuropsychopharmacology, 25(5), 766-776. https://doi.org/10. 1016/S0893-133X(01)00278-0

Hinson, J. M., Jameson, T. L., \& Whitney, P. (2003). Impulsive decision making and working memory. Journal of Experimental Psychology: Learning, Memory, and Cognition, 29(2), 298-306. https://doi.org/ 10.1037/0278-7393.29.2.298

Holm, S. (1979). A simple sequentially rejective multiple test procedure. Scandinavian Journal of Statistics, 6, 65-70. https://www.jstor.org/ stable/4615733

Jaroni, J. L., Wright, S. M., Lerman, C., \& Epstein, L. H. (2004). Relationship between education and delay discounting in smokers. Addictive Behaviors, 29(6), 1171-1175. https://doi.org/10.1016/j. addbeh.2004.03.014

Jonassaint, C. R., Siegler, I. C., Barefoot, J. C., Edwards, C. L., \& Williams, R. B. (2011). Low life course socioeconomic status (SES) is associated with negative NEO PI-R personality patterns. International Journal of Behavioral Medicine, 18, 13-21. https:// doi.org/10.1007/s12529-009-9069-х

Kirby, K. N., Winston, G. C., \& Santiesteban, M. (2005). Impatience and grades: Delay-discount rates correlate negatively with college GPA. Learning and Individual Differences, 15(3), 213-222. https://doi. org/10.1016/j.lindif.2005.01.003

MacKillop, J., Amlung, M. T., Few, L. R., Ray, L. A., Sweet, L. H., \& Munafò, M. R. (2011). Delayed reward discounting and addictive behavior: A meta-analysis. Psychopharmacology, 216(3), 305-321. https://doi.org/10.1007/s00213-011-2229-0

MacKillop, J., Weafer, J., Gray, J. C., Oshri, A., Palmer, A., \& de Wit, H. (2016). The latent structure of impulsivity: Impulsive choice, impulsive action, and impulsive personality traits. Psychopharmacology, 233(18), 3361-3370. https://doi.org/10.1007/s00213-016-4372-0

Mahalingam, V., Stillwell, D., Kosinski, M., Rust, J., \& Kogan, A. (2014). Who can wait for the future? A personality perspective. Social Psychological and Personality Science, 5(5), 573-583. https://doi.org/10.1177/1948550613515007

Manning, J., Hedden, T., Wickens, N., Whitfield-Gabrieli, S., Prelec, D., \& Gabrieli, J. D. (2014). Personality influences temporal discounting preferences: Behavioral and brain evidence. NeuroImage, 98, 42-49. https://doi.org/10.1016/j.neuroimage. 2014.04.066

McCrae, R. R., \& Costa, P. T. Jr. (2004). A contemplated revision of the NEO Five-Factor Inventory. Personality and Individual 
Differences, 36(3), 587-596. https://doi.org/10.1016/S01918869(03)00118-1

Myerson, J., \& Green, L. (1995). Discounting of delayed rewards: Models of individual choice. Journal of the Experimental Analysis of Behavior, 64(3), 263-276. https://doi.org/10.1901/jeab.1995.64263

Myerson, J., Green, L., \& Warusawitharana, M. (2001). Area under the curve as a measure of discounting. Journal of the Experimental Analysis of Behavior, 76(2), 235-243. https://doi.org/10.1901/jeab. 2001.76-235

Reynolds, B., Ortengren, A., Richards, J. B., \& de Wit, H. (2006). Dimensions of impulsive behavior: Personality and behavioral measures. Personality and Individual Differences, 40(2), 305-315. https://doi.org/10.1016/j.paid.2005.03.024

Shah, A. K., Mullainathan, S., \& Shafir, E. (2012). Some consequences of having too little. Science, 338(6107), 682-685. https://doi.org/10. 1126/science. 1222426

Shamosh, N. A., \& Gray, J. R. (2008). Delay discounting and intelligence: A meta-analysis. Intelligence, 36(4), 289-305. https://doi. org/10.1016/j.intell.2007.09.004

Shamosh, N. A., DeYoung, C. G., Green, A. E., Reis, D. L., Johnson, M. R., Conway, A. R. A., ... Gray, J. R. (2008). Individual differences in delay discounting: Relation to intelligence, working memory, and anterior prefrontal cortex. Psychological Science, 19(9), 904-911. https://doi.org/10.1111/j.1467-9280.2008.02175.x
Slotkin, J., Kallen, M., Griffith, J., Magasi, S., Salsman, H., Nowinski, C., \& Gershon, R. (2012). NIH toolbox technical manual. Bethesda, MD: National Institutes of Health. http://www.healthmeasures.net/ images/nihtoolbox/Technical_Manuals/Sensation/Toolbox_ VRQOL_Survey_Technical_Manual.pdf

Spinella, M. (2005). Self-rated executive function: Development of the executive function index. International Journal of Neuroscience, 115(5), 649-667. https://doi.org/10.1080/00207450590524304

Stanford, M. S., Mathias, C. W., Dougherty, D. M., Lake, S. L., Anderson, N. E., \& Patton, J. H. (2009). Fifty years of the Barratt Impulsiveness Scale: An update and review. Personality and Individual Differences, 47(5), 385-395. https://doi.org/10.1016/j. paid.2009.04.008

Van Essen, D. C., Smith, S. M., Barch, D. M., Behrens, T. E., Yacoub, E., Ugurbil, K., \& WU-Minn HCP Consortium. (2013). The WU-Minn human connectome project: An overview. NeuroImage, 80, 62-79. https://doi.org/10.1016/j.neuroimage.2013.05.041

Weatherly, J. N., \& Ferraro, F. R. (2011). Executive functioning and delay discounting of four different outcomes in university students. Personality and Individual Differences, 51(2), 183-187. https://doi. org/10.1016/j.paid.2011.03.042

Publisher's note Springer Nature remains neutral with regard to jurisdictional claims in published maps and institutional affiliations. 